Int. J. Dev. Biol. 48: 819-827 (2004)

doi: $10.1387 / \mathrm{ijdb} .041868 \mathrm{hk}$

\title{
Interplay of Pax6 and SOX2 in lens development as a paradigm of genetic switch mechanisms for cell differentiation
}

\author{
HISATO KONDOH*, MASANORI UCHIKAWA and YUSUKE KAMACHI \\ Graduate School of Frontier Biosciences, Osaka University, 1-3 Yamadaoka, Suita, Osaka 565-0871, JAPAN
}

\begin{abstract}
When the cloning era arrived, our first target for cloning was the $\delta 1$-crystallin gene of the chicken, the lens-specific gene expressed earliest following lens induction. We have investigated the regulation of this gene with the idea that the mechanism of its activation must reflect that of lens differentiation per se. We here summarize the investigation carried out in our group along this line over the past 20 years. The $\delta 1$-crystallin gene is regulated by an enhancer in the third intron, and the specificity of this regulation is governed by a DNA region (called DC5) of only 30 bp DNA bound by two transcription factors. These factors have been identified as SOX1/2/3 (Group B1 SOX proteins, SOX2 being the major player) and Pax6, and have been shown to bind cooperatively to DC5 and form a ternary complex having a robust potency for transcriptional activation. In the embryo, Pax6 is widely expressed in the head ectoderm before the lens is formed, and as the optic vesicle comes into contact with the ectoderm, SOX2/3 expression is induced in the contacted area of the ectoderm, thereby allowing Pax6 and SOX2/3 to meet in the same cell nucleus, where they can then activate a battery of genes for early lens development including $\delta 1$ crystallin. Thus, the cooperative action of Pax6 and SOX2 initiates lens differentiation. More broadly, SOX1/2/3 interact with various partner transcription factors, and participate in defining distinct cell states that depend on the partner factors: Pax6 for lens differentiation, Oct3/4 for establishing the epiblast/ES cell state, and Brn2 for the neural primordia. Thus, the regulation of SOX2 (and SOX1/3) and its partner factors, exemplified by Pax6, determines the spatio-temporal order of the occurrence of cell differentiation.
\end{abstract}

KEY WORDS: $\delta$-crystallin, lens, Pax6, SOX2, enhancer

\section{Prelude}

Eye lenses are derived from head ectoderm, being induced by an effect of the optic vesicle, the retinal primordia extruding from the embryonic diencephalon. Lens develops as a remarkably transparent tissue, rich in a group of proteins collectively called crystallins. Crystallins are excellent molecular markers of lens differentiation, and have made it possible to study ectodermderived lens development as a paradigm of tissue differentiation. During the early period of modern cell differentiation studies, when cell types began to be defined on the basis of specific molecular constituents of the cells, specific anti-crystallin antibodies provided the sharpest molecular tools for the analysis of lens differentiation (Clayton and Truman, 1967; Clayton, 1970). Later, Rot analysis of crystallin cDNAs became available, and the beautiful work using this technique done by Shinohara and Piatigorsky (Shinohara and Piatigorsky, 1976) was the prelude of the real modern age of the study of lens development. Their work demonstrated that the $\delta 1$ - crystallin gene is activated soon after the lens is induced in the head ectoderm by contact with the optic vesicle (retina primordium) extruding from the diencephalons. This also corroborated earlier immunochemical observations that $\delta 1$-crystallin is the first crystallin synthesized in lens development.

\section{The cloning age and $\delta 1$-crystallin regulation}

Then the cloning age arrived. Our first target of gene cloning was the $\delta 1$-crystallingene of the chicken, because it was the earliest lensspecific gene to be turned on after lens induction. The idea behind this was that the mechanism of activating this gene must be deeply involved in the early process of lens differentiation, perhaps the lens induction process itself. Once the whole genomic stretch of the gene for $\delta 1$-crystallinwas isolated by two groups including us (Bhat, et al., 1980; Jones, et al., 1980; Yasuda, et al., 1982; Yasuda, et al., 1984), we proceeded to test if the cloned gene in the form of naked DNA shows cell specificity after introduction into living cells.

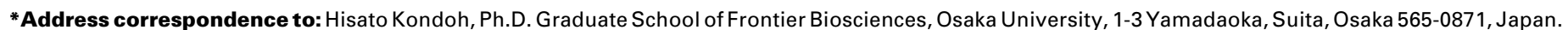
Fax: +81-6-6877-1738. e-mail: j61056@hpc.cmc.osaka-u.ac.jp
} 


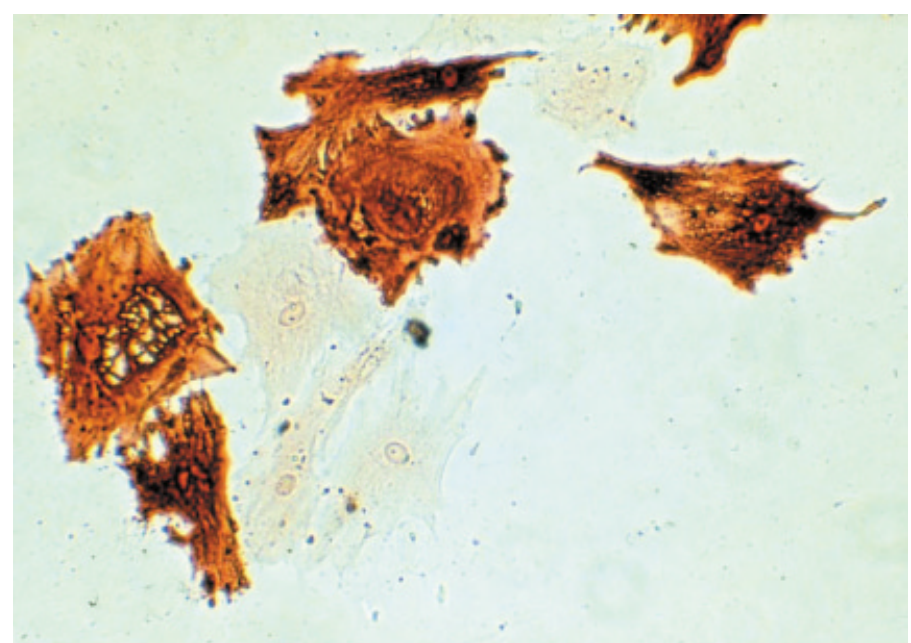

Fig. 1. Expression of the chicken $\delta 1$-crystallin in mouse lens epithelial cells detected by immunohistology (Kondoh, et al., 1983). Full-length $\delta 1$-crystallin gene was injected into the nucleus of a variety of mouse cells lacking this gene, and $\delta 1$-crystallin expression was detected by immunohistology. Among the mouse cells in primary cultures, only lens cells expressed this crystallin strongly, as shown in this figure. The rate of synthesis of $\delta 1$-crystallin per gene was comparable between the injected mouse lens epithelial cells and chicken lens epithelial cells expressing endogenous crystallins.

The strategy we employed was nuclear microinjection of the cloned $\delta 1$-crystallin gene of the chicken into a variety of mouse cells in primary culture (Kondoh, et al., 1983), taking advantage of the fact that mouse lens is devoid of the $\delta 1$-crystallin gene, thus allowing sensitive detection of $\delta 1$-crystallin expression by immunochemical means. Expression of the $\delta 1$-crystallin gene derived from the chicken was highly lens-specific in mouse cells (Fig. 1), indicating first that genetic elements involved in lensspecific gene regulation must be present in the stretch of the cloned gene, and second that the regulatory mechanism for lens-specific gene regulation must be conserved between the mouse and the chicken, although the $\delta 1$-crystallingene is missing in the mouse.

This was one of the earliest demonstrations that cloned genes retain the original cell specificity of expression after introduction into living cells. Lens-specific $\delta 1$-crystallin expression was later confirmed in transgenic mice (Kondoh, et al., 1987; Takahashi, et al., 1988). This demonstration was also the starting point for hunting for the lens-specific regulatory sequences associated with the $\delta 1$-crystallingene.

The transcribed sequence of the $\delta$-crystallingene is $9 \mathrm{~kb}$ long and consists of 17 exons, and the cloned sequence included a 15kb-long 5' flanking sequence and 4-kb-long 3' flanking sequence. After several years' attempts (Kondoh, et al., 1984; Hayashi, et al., 1985 ), we came to the clear conclusion that the $\delta$-crystallingene is primarily regulated by the lens-specific enhancer located in the third intron (Hayashi, et al., 1987) (Fig. 2).

The enhancer itself is $1 \mathrm{~kb}$ long, but its activity is totally dependent on the core region called DC5, which is only 30 bp long. The DC5 sequence by itself shows lens-specific enhancer activity, although it is much weaker than that of the full-length enhancer, and the lens-specific enhancer activity is clearly demonstrable using its multimeric forms (Goto, et al., 1990; Funahashi, et al., 1991; Kamachi and Kondoh, 1993).
The first nuclear factor cloned based on its specific binding to the DC5 sequence was $\delta E F 1$ (also called ZEB (Genetta, et al., 1994)), which has two zinc finger clusters and a homeodomain, and which became the vertebrate founder of ZFHX1 family transcription factors (Funahashi, etal., 1991; Funahashi, etal., 1993). $\delta E F 1$ has activity as a transcriptional repressor (Funahashi, et al., 1993; Sekido, et al., 1994; Sekido, et al., 1997; Furusawa, et al., 1999), and may modulate $\delta$-crystallinenhancer activity. $\delta \mathrm{EF} 1$ and another ZFHX1 protein, SIP1, have been shown to have many roles in embryonic organogenesis (Sekido, et al., 1994; Higashi, et al., 1997; Takagi, et al., 1998; Van De Putte, et al., 2003).

\section{SOX1/2/3 as activators of crystallin genes}

Mutational analysis of the DC5 sequence indicated that there are two activating nuclear factors, $\delta \mathrm{EF} 2$ and $\delta \mathrm{EF} 3$, binding to this sequence next to each other, and the simultaneous binding of these factors is essential for the enhancer activity (Kamachi and Kondoh, 1993). Mutations in either one of the two factor binding sites caused the complete loss of enhancer activity.

A search for $\delta E F 2$ was done employing the southwestern cloning strategy, and it was identified as Group B1 SOX proteins SOX1, SOX2 and SOX3, all of which have analogous amino acid sequences, and among which SOX2 is the major component (Kamachi, et al., 1995; Kamachi et al., 1998) (Fig. 2). Any one of them can activate the DC5 enhancer in lens cells, where the partner factor $\delta E F 3$ must be present, but this activation does not occur in fibroblasts, where $\delta E F 3$ is presumably absent. In the lens, SOX2 is the major molecular species of $\delta E F 2$ (Kamachi, et al., 1995; Uchikawa, et al., 1999). Other SOX proteins such as SOX9 or SOX11 do not activate the DC5 $\delta$-crystallin-enhancer, indicating that $\delta \mathrm{EF} 2$ function is restricted to the Group B1 SOX proteins (Kamachi, et al., 1998; Kamachi, et al., 1999).

The actions of Group B1 SOX proteins are not limited to activation of the $\delta$-crystallin gene, but are also essential for the activation of $\gamma$-crystallingenes in the mouse lens (Kamachi, et al., 1995; Nishiguchi, et al., 1998). $\gamma$-crystallin promoters have two conserved sequence motifs for binding of SOX $1 / 2 / 3$ and another protein initially called $\gamma-\mathrm{F} 1$, and the integrity of both motifs is essential for the activity of $\gamma$-crystallin promoters (Lok, et al., 1989; Liu, et al., 1991; Kamachi, et al., 1995). $\gamma-\mathrm{F} 1$ has now been identified as Maf proteins (Ogino and Yasuda, 1998; Kawauchi, et al., 1999; Kim, et al., 1999; Kondoh, 1999), as will be discussed below.

\section{Pax6 as the partner of SOX1/2/3}

The second activating nuclear factor, $\delta \mathrm{EF} 3$, was rather difficult to clone, presumably because the binding of $\delta E F 3$ alone was very weak (strong binding of $\delta \mathrm{EF} 3$ might depend on the presence of the partner factor SOX2). We therefore set up a functional two-protein interaction assay in yeast cells where reporter genes HIS3 or lacZ are activated when $\delta E F 3$ expressed from a cDNA library meets SOX2 or SOX 1 in the same cells. SOX 2 or SOX 1 proteins were first expressed in yeast cells, and then lens-derived cDNAs in the form of fusion constructs with the GAL4 activation domain were introduced. In this assay system, if the cDNA for $\delta E F 3$ is introduced, it will activate the selection gene HIS 3 with the aid of a SOX protein. This screen was successful, and $\delta E F 3$ was identified as Pax 6 (Fig. 2). In yeast cells, SOX1, SOX2 and SOX3 cooperated with Pax6 in 

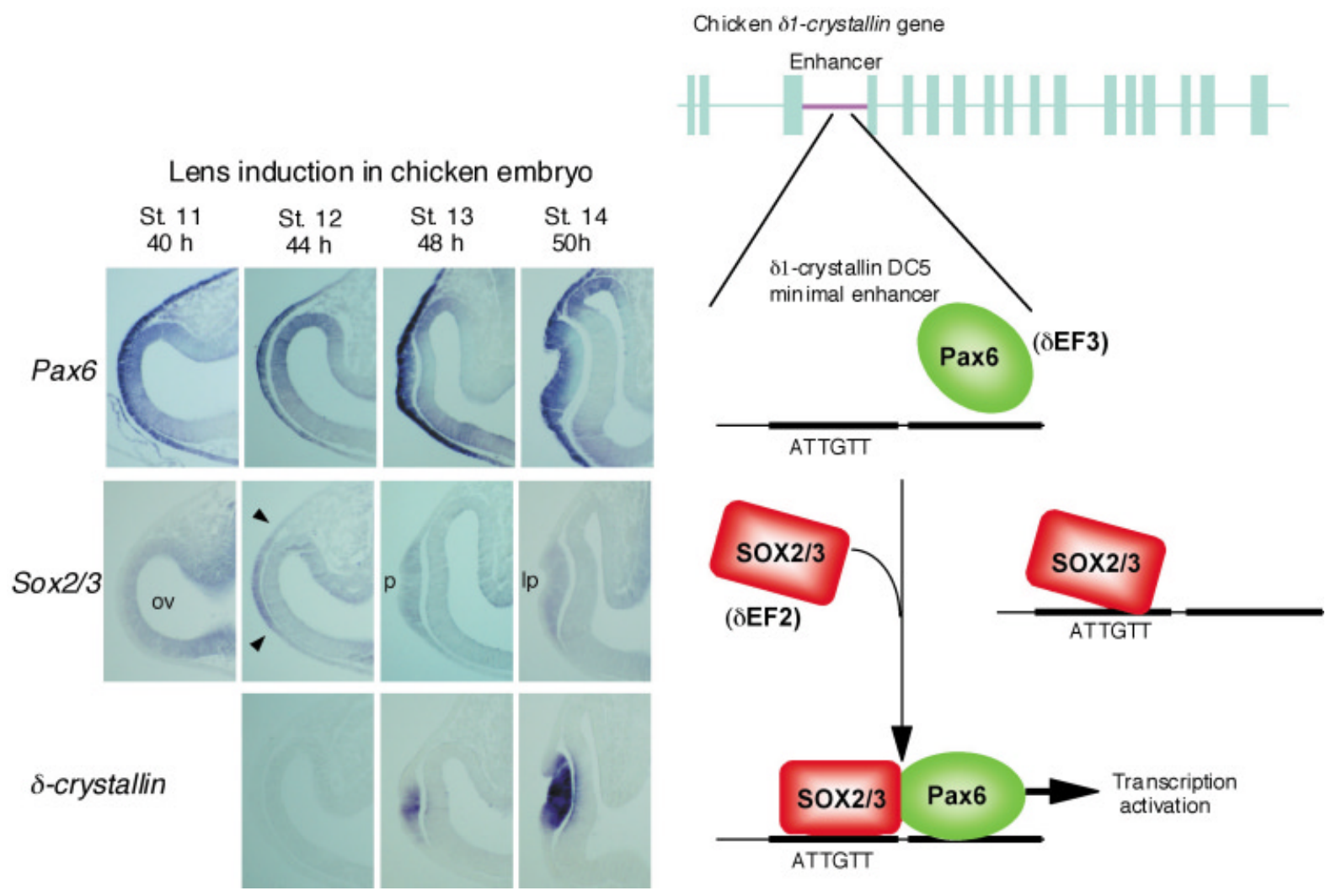

Fig. 2. Regulation of $\boldsymbol{\delta 1 - c r y s t a l l i n ~ g e n e ~ b y ~ c o o p e r a t i v e ~ a c t i o n ~ o f ~ P a x 6 ~ a n d ~ S O X 2 ~ ( K a m a c h i , ~ e t ~ a l . , ~ 1 9 9 8 ; ~ K a m a c h i , ~ e t ~ a l . , ~ 2 0 0 1 ) . ~ ( R i g h t ) ~ L e n s - s p e c i f i c ~}$ $\delta 1$-crystallin expression is regulated by the enhancer in the third intron of the gene. The activity of this gene is dictated by the 30-bp DC5 region, which by itself shows a lens-specific enhancer activity when present as a multimeric form. The DC 5 minimal enhancer is regulated by the cooperative action of Pax6 and SOX2, which bind next to each other at their respective sites in the DC5 sequence. (Left) In the embryo, Pax6 is initially expressed broadly in the head ectoderm, and contact by the optic vesicle (retina primordium) at stage 11 induces SOX2 (and SOX3 in the chicken) in the same ectoderm (st. 12). This results in cooperative action of Pax 6 and SOX 2 at the target sites, and initiates lens development, as indicated by $\delta 1$-crystallin expression and lens placode morphogenesis. [Histological images are reproduced from Kamachi et al. (1998), Involvement of Sox1, 2 and 3 in the early ad subsequent molecular events of lens induction. Development 125, 2521-2532, Fig. $5 B$ with permission from The Company of Biologists Limited.]

the activation of DC5, while other SOX proteins, like SOX9, did not, confirming the expected specificity of the $\delta E F 2-\delta E F 3$ interaction (Kamachi, et al., 2001).

In the DC5 sequence, the binding sites for SOX2 and Pax6 are adjacent. The SOX2 binding site sequence conforms to the SOX consensus sequence, while the Pax 6 binding site sequence shows only limited similarity to the Pax6 PD (paired domain) binding consensus sequence. This results in very weak binding of the Pax6 $\mathrm{PD}$ alone to the DC5 site, with two orders of magnitude lower affinity than to the Pax6 PD consensus, as assessed by EMSA (electrophoretic mobility shift assay). However, when a small amount of SOX2 is included in the reaction, a low concentration of Pax6 is sufficient to form a ternary complex with SOX and the DC5 DNA, indicating that Pax 6 binds to the DC5 sequence cooperatively with SOX2 (Fig. 3).

SOX2 and Pax6 not only bind to the DC5 sequence with high cooperativity, but they activate the enhancer interdependently. In lens cells, which contain endogenous SOX2 and Pax6, the DC5 minimal enhancer has some activity without exogenous SOX2 or Pax6, but an exogenous supply of these proteins dramatically augmented the activation level. In liver cells, which lack these factors, single addition of SOX2 or Pax 6 did not activate the DC5 enhancer at all, and a simultaneous supply of both SOX2 and Pax6 together activated the enhancer to a level comparable to that in the lens cells (Kamachi, et al., 2001). Thus, SOX2 and Pax6, when they bind to the DC5 sequence as a complex, are sufficient for activation of the DC5 enhancer.

Interestingly, however, when the Pax6 binding sequence of DC5 was replaced by the high-affinity Pax6 PD consensus sequence, the modified DC5 sequence bound Pax 6 very well, but cooperative binding with SOX2 did not occur, and activation of the enhancer remained very low even at a high concentration of Pax6, and was totally independent of the presence of SOX2. A separate experiment revealed that the activation domains of Pax 6 and SOX proteins do not function individually but organize a compound activation domain. This compound activation domain is highly potent and responsible for the high level of activation of the DC5 enhancer by Pax6 and SOX2. Thus, by having the unique Pax6 binding sequence deviating from the consensus, the DC5 sequence organizes the ternary complex with Pax6 and SOX2 into a specific structure for robust gene activation (Kamachi, et al., 2001).

\section{Combined action of Pax6 and SOX2 in lens induction}

How is the cooperative action of Pax6 and SOX2 involved in early lens development? Lens placode develops from the lateral 
head ectoderm when inductive signals are provided by the optic vesicle, which makes a transient contact with the head ectoderm. Even before the occurrence of lens induction, Pax6 is already expressed in a wide area of the head ectoderm, including the prospective lens placode region (Li, et al., 1994; Kamachi, et al., 1998). It is well known that Pax6mutant heterozygous mice display a small eye phenotype, and homozygous mutant mice are totally defective in lens placode induction (Hogan, et al., 1986; Hill, et al., 1991; Grindley, et al., 1995), and in humans, an analogous genetic situation causes aniridia (Jordan, et al., 1992). The optic vesicle also expresses Pax6, but tissue recombination experiments demonstrated that Pax6 in the ectoderm is essential for lens placode development (Fujiwara, et al., 1994).

Once the optic vesicle makes contact with the head ectoderm, the Sox 2 and Sox 3 genes (in chickens; only Sox 2 in mice) are activated in the ectoderm only in the region of contact, and they immediately initiate synthesis of the encoded proteins. This region of the head ectoderm expressing SOX2 and Pax6 together gives rise to the lens placode (Kamachi, et al., 1998).

Thus, in embryonic lens development, the induction of SOX2 (and SOX3) in the Pax6-expressing head ectoderm allows SOX2/
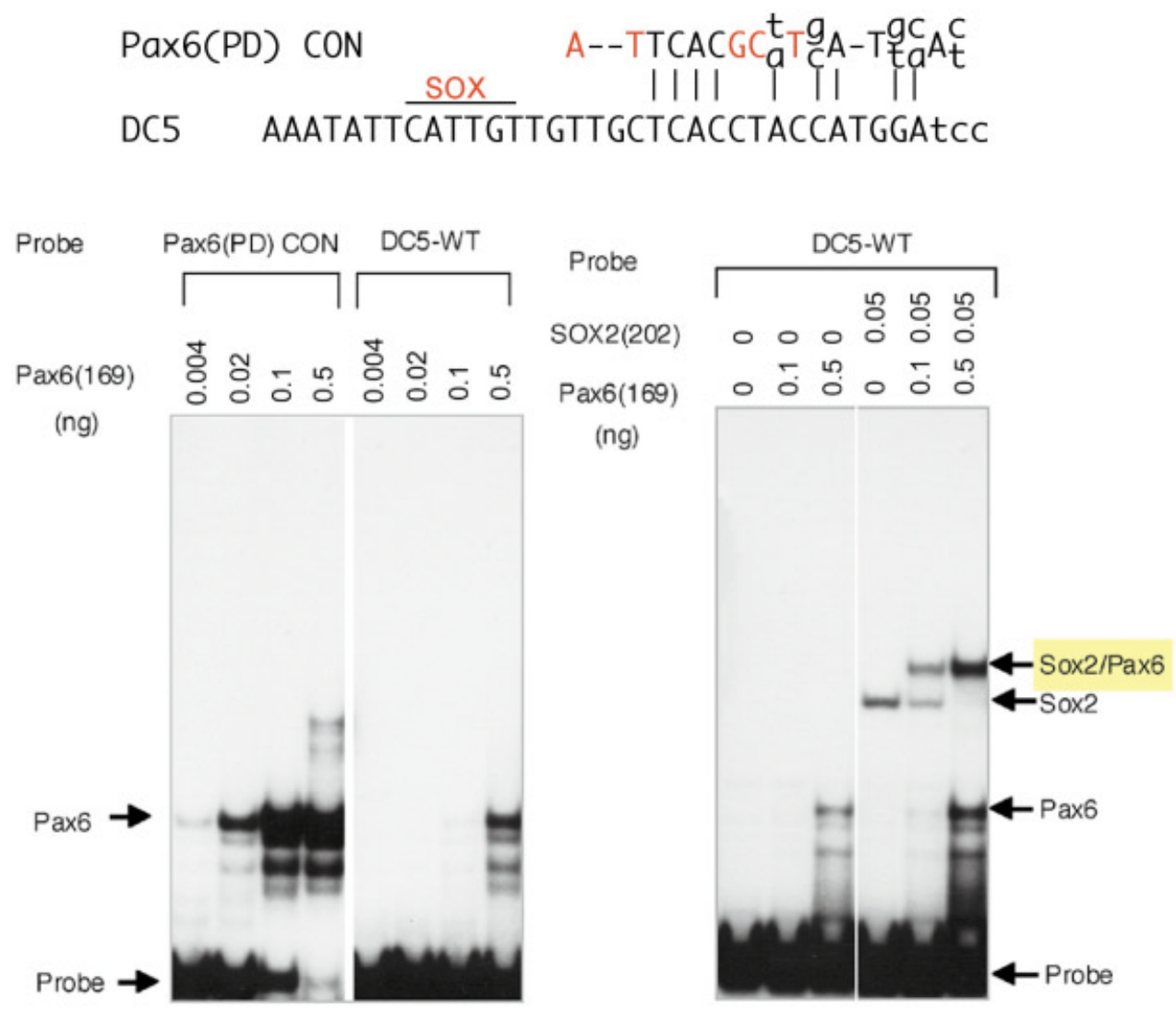

Fig. 3. Cooperative binding of Pax6 and SOX2 to the DC5 sequence (Kamachi, et al., 2001). Comparison of the Pax6 binding site of the DC5 minimal enhancer with the Pax6 PD (paired domain) binding consensus (top) reveals significant sequence diversification. In electrophoretic mobility shift assay (EMSA), Pax6 PD in alone binds very weakly to the DC5 sequence (left panel), but in the presence of SOX2, Pax6 binds to the DC5 sequence with high affinity in cooperation with SOX2 (right panel). [Adopted from Kamachi et al. (2001), Pax6 and SOX2 form a co-DNA-binding partner complex that regulates initiation of lens development. Genes \& Development 15, 1272-1286, Fig. 2 with permission from Cold Spring Harbor Laboratory Press.]
3 proteins to meet Pax 6 in the same cell nucleus. This interaction initiates lens placode development and activates the $\delta 1$-crystallin gene. "Lens competence" of the head ectoderm in classical terms corresponds to Pax6 expression in the ectoderm, and the classical "lens induction" is actually induction of Sox $2 / 3$ expression in the ectoderm (Kamachi, et al., 2001) (Fig. 2).

To confirm that the combined action of SOX2 and Pax6 elicits lens development starting from placode development, we performed studies using chicken embryo electroporation. Stage 10 embryos mediately before the occurrence of lens induction were troporated with DNA in the lateral head ectoderm. With Pax6 1-crystallindeveloped in the embryo surface outside of the eye, and ese cell clusters had the characteristics of lens placode: a thickened in structure with expression of placode markers in addition to 4). Therefore, the pair of the transcription factors Pax6 and SOX2 not the $\delta 1$-crystallin gene, but in fact initiates lens development starting from the head ectoderm.

\section{Early regulatory cascades of lens development involving Pax6 and SOX2}

Recent investigations support the notion that the Pax6-SOX2 pair regulates more steps of lens development. It was noted that exogenous and ectopic expression of SOX2 in Pax6-expressing head ectoderm results in the stabilization of Pax6 expression (Kamachi, et al., 2001), suggesting that a Pax6 maintenance mechanism depends on SOX2 activity. A genetic element of the Pax6 gene that function in the maintenance of Pax6expression in the lens lineage was identified, and this element is also activated by the combination of Pax6 and SOX2 (Aota, et al., 2003).

Dr. K. Yasuda's group has also studied crystallin gene regulation, employing $\alpha$-crystallin genes as a model, and has highlighted the importance of Maf family transcription factors, L-Maf in particular, in chicken lens development (Ogino and Yasuda, 1998). Recent work of this group demonstrated that L-Maf transcription is activated by the combined action of Pax6 and SOX2(Reza, et al., 2002), again confirming that the action of the Pax6-SOX2 pair occurs the furthest upstream of the cascades of events leading to lens development (Fig. 5).

Dr. Yasuda's group has also found that once Maf protein genes are 


\section{Electroporation of chicken head ectoderm with Sox2 and Pax6}

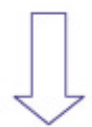

\section{Ectopic lens placode development}

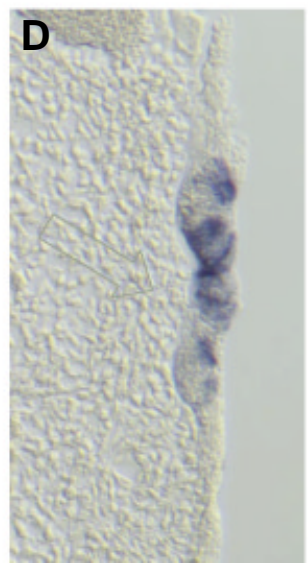

A
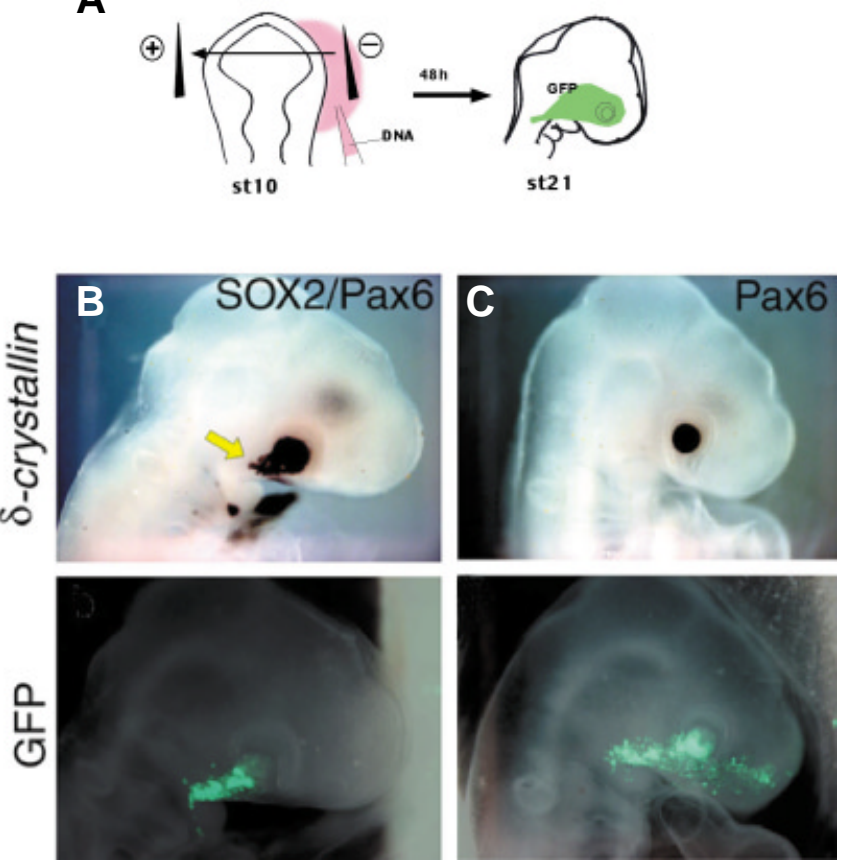

Fig. 4. Exogenous expression of Pax6 and SOX2 in the head ectoderm causes ectopic development of lens placode (Kamachi et al., 2001). Electroporation of chicken embryo head ectoderm (A) with expression vectors for Pax 6 and Sox 2 resulted in cell clusters expressing $\delta 1$-crystallin outside of the eye (B) (arrow), while electroporation with Pax6 vector alone did not have such an effect (C). Histological sections show lens placodelike morphology of the cell clusters with ectopic $\delta 1$-crystallin expression (D). [Adopted from Kamachi et al. (2001), Pax6 and SOX2 form a co-DNAbinding partner complex that regulates initiation of lens development. Genes \& Development 15, 1272-1286, Fig. 6 with permission from Cold Spring Harbor Laboratory Press.]

activated, Maf and SOX1/2/3 proteins cooperate and promote lens differentiation (Shimada, et al., 2003). This is consistent with the previous observations that SOX $1 / 2 / 3$ and Maf $(\gamma \mathrm{F}-1)$ binding sites in the promoters are essential for $\gamma$-crystallin gene transcription (Lok, et al., 1989; Liu, et al., 1991; Kamachi, et al., 1995) and that Maf proteins function primarily in the lens fibers (Kawauchi, et al., 1999; Kim, et al., 1999; Ring, et al., 2000; Muta, et al., 2002).

\section{Lens can arise from adenohypophysis primordium}

Initiation of lens development by the cooperative action of Pax6 and SOX2 also accounts for lens differentiation through nonorthodox pathways, often referred to as transdifferentiation (Okada, et al., 1979; Okada, 1980). For instance, lenses efficiently differentiate from embryonic neural retina under culture conditions (Okada, 1980; Kondoh, etal., 1987). This is likely due to endogenous co-expression of Pax6 and SOX2.

It is known that Rathke's pouch, the primordium of the adenohypophysis, transiently expresses $\delta 1$-crystallin (Fedtsova, et al., 1981; Ueda and Okada, 1986; Kamachi, et al., 1998). We noted that Rathke's pouch simultaneously expresses Pax6 and
SOX2, and hypothesized that this combination of transcription factors not only activates crystallin genes but potentiates lens differentiation (Kamachi, et al., 1998), and that under certain conditions the pouch might be able to lens differentiation.

This hypothesis was proven true by analysis of a zebrafish mutant called you-too (yot), which develops isolated lenses from adenohypophysis primordium without association of retinal tissue (Kondoh, et al., 2000) (Fig. 6). This mutant expresses a dominantnegative form of the Gli2 transcription factor that interferes with hedgehog (Karlstrom, et al., 1999). Lens development from adenohypophysis primordium under the condition of attenuated

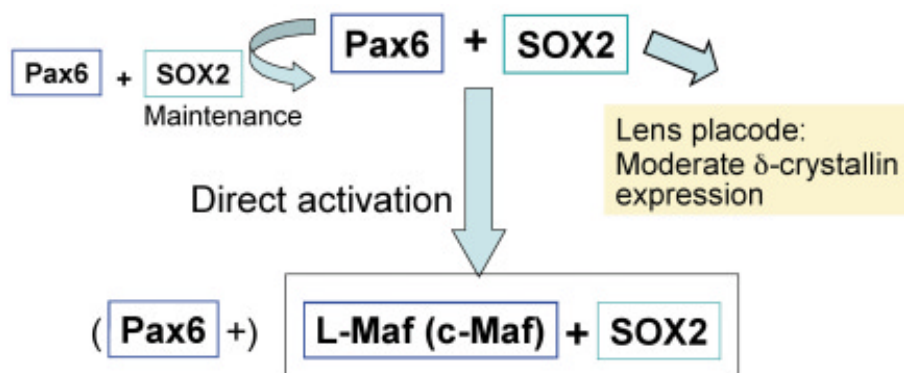

Fig. 5. Early regulatory cascades of lens development involving Pax6 and SOX2. Besides direct activation of lens-specific genes, the cooperative action of Pax 6 and SOX2 also induces another group of transcription factors belonging to the Maf family (L-maf in the chicken (Shimada, et al., 2003)) and reactivates Pax6 to maintain its high-level expression in the lens cells (Aota, et al., 2003). Maf and SOX2 (possibly with the participation of Pax6) then activate other lens-specific genes (e.g., $\gamma$-crystallin in the mouse (Kamachi, et al., 1995)) and augment $\mathbf{1} 1$-crystallin expression (Muta, et al., 2002).

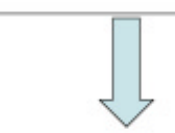

Lens fibers:

High $\delta$-crystallin expression 


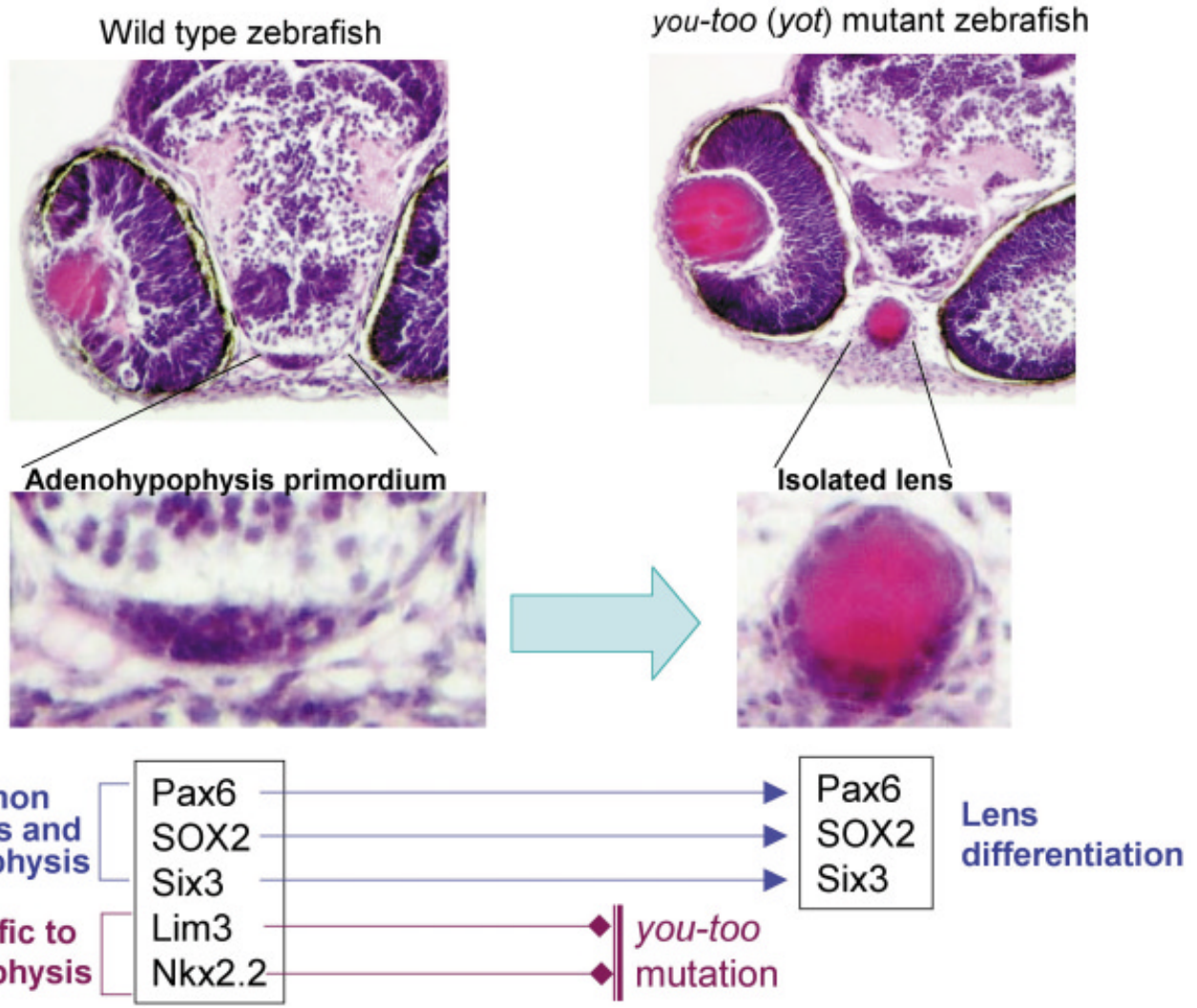

Fig. 6. Embryonic tissues expressing Pax6 and SOX2 have the potential to develop into lens. The primordium of the adenohypophysis (Rathke's pouch in the mouse and chicken) expresses Pax6 and SOX2. In zebrafish mutants defective in shh signaling, the hypophysis primordium fails to express hypophysis-proper transcription factors, e.g., Lim 1 and Nkx2.2, and develops into lens (Kondoh, et al., 2000; Varga, etal., 2001). [Adopted from Kondoh et al. (2000), Zebrafish mutations in Glimediated hedgehog signaling lead to lens transdifferentiation from the adenohypophysis anlage. Mechanisms of Development 96, 165-174, Fig. 1 with permission from Elsevier.] hedgehog signaling was confirmed by analysis of smoothened zebrafish mutant embryos (Varga, et al., 2001). Looking into the literature published in the 60s, we found that embryos of talpid3 mutant chickens also develop lenses from Rathke's pouch (Ede and Kelly, 1964). The talpid3 mutant is now known to be defective in hedgehog signaling (Lewis, etal., 1999). Thus, the adenohypophysis primordium has the potential for lens differentiation owing to expression of Pax6 and SOX2, but this potential is presumably inhibited by hedgehog signal derived from surrounding tissues, in particular from the hypothalamus, and hypophysis differentiation is activated by expression of hypophysis-proper transcription factors, e.g., Lim3 and Nkx2.2 (Kondoh, et al., 2000).

\section{Steps of Sox2 regulation during lens induction}

One of the major issues concerning early lens development then becomes how the Sox2gene is regulated in the lens lineage. Before lens induction, Sox2is initially expressed at modest levels in the lateral head ectoderm as an extension of the ventral expression. Via an effect of the optic vesicle, strong Sox2expression is induced in the lateral ectoderm, leading to lens placode development. Even stronger Sox2 expression is activated in the fiber cells of maturing lenses. Thus, there appear to be multiple steps of Sox2 regulation.

We sought to define these steps by identifying enhancers responsible for these individual steps. To this end, we cloned a wide genomic region encompassing the Sox2gene of the chicken, prepared a number of small fragments that altogether spanned the whole region, placed the fragments in a reporter expressing GFP, and electroporated it into chicken embryos from stage 4 to stage 7 .
We then examined the expression of GFP in the embryos as test for the enhancer activity of the inserted genomic fragment (Uchikawa, et al., 2003).

The Sox2gene itself is expressed not only in the lens lineage but also in the CNS. We identified a number of enhancers responsible for Sox2expression in various domains of the CNS and in different stages of lens development, as summarized in Fig. 7.

Early Sox2expression in the head ectoderm that occurs before lens induction is accounted for by the activity of enhancer $\mathrm{N}-4$, which is located roughly $22 \mathrm{~kb}$ downstream of the gene and is also active in the early mesencephalon and the spinal cord. Enhancer $\mathrm{N}-3$ (responding to the lens induction) is located upstream of the gene. The same enhancer is active in the diencephalon and the retina as well. The activity of this enhancer in the lens is short-lived, and fades very quickly as the vesicular lens develops. Enhancer $L$, located further downstream of the gene, supports Sox2expression in the lens fiber.

Thus, the three steps of Sox2expression, modest expression in the early head ectoderm, augmentation in response to lens induction, and further activation later in the lens, are defined by three distinct enhancers. Each of these enhancers has been narrowed down to a few hundred base pairs. Identification of the nuclear factors binding to these enhancers will clarify which signals are directly involved in the activation of the Sox2gene during lens induction.

We determined the whole nucleotide sequence of the $50-\mathrm{kb}$ region surrounding the Sox2gene of the chicken, and compared it with those of the Sox2locus in the mouse and human genomes. We observed scattered but linearly arranged islands of sequences, usually a few hundred base pairs long, that are conserved between chickens and mammals. Significantly, many of these islands of 

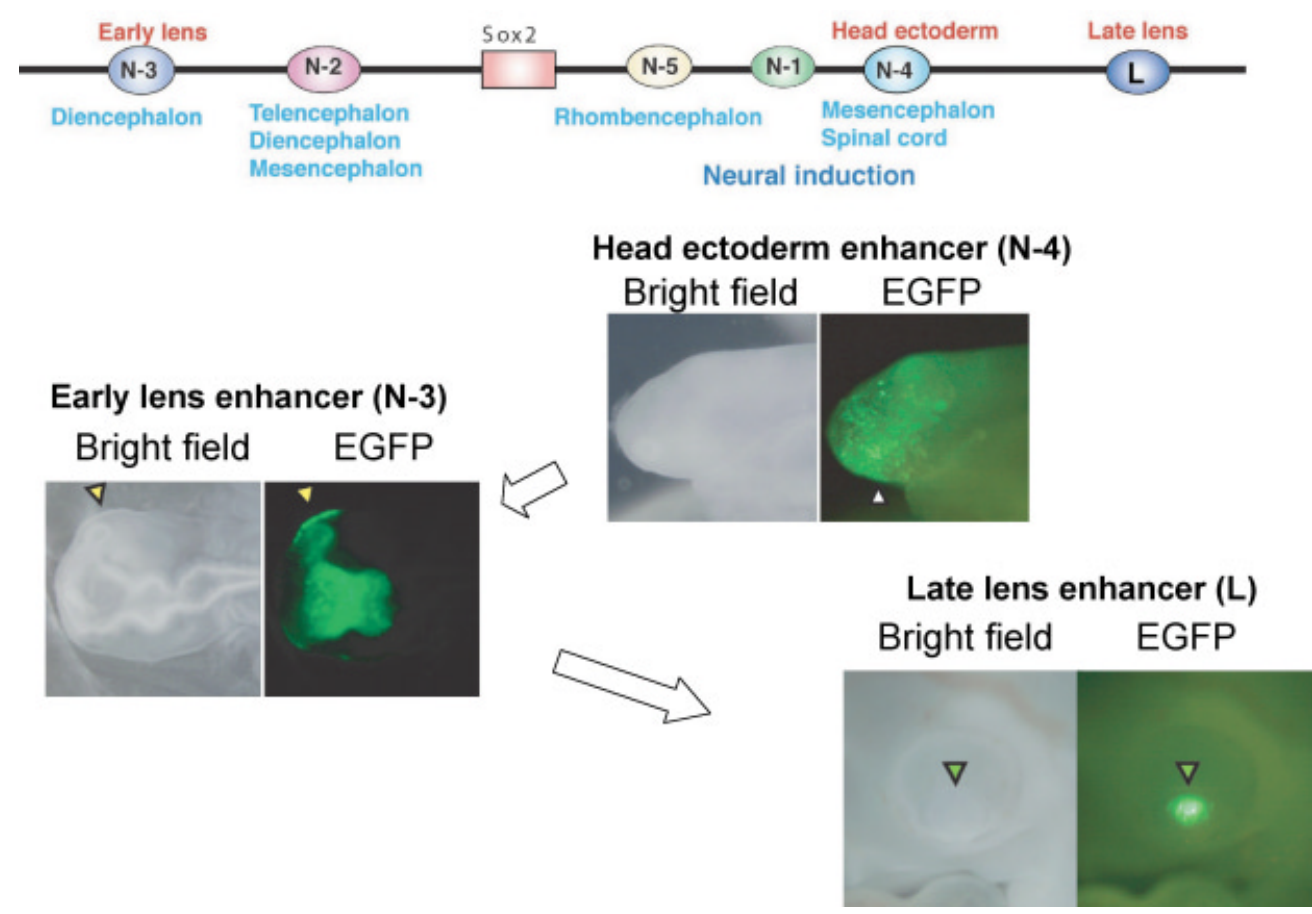

Fig. 7. (Above) Enhancers of the Sox2 gene regulating three different phases of lens development in the chicken (Uchikawa et al., 2003). Enhancer N-4 is responsible for moderate Sox 2 expression in the ventral half of the head ectoderm before lens induction occurs. Enhancer N-3, which is activated by contact with the optic vesicle, accounts for the surge of Sox2 expression in the ectodermal area forming the lens placode, and this enhancer maintains its activity until lens vesicle stage. The third enhancer $L$, not present in mammals, activates Sox2 in the lens fiber.

SOX Partner factor

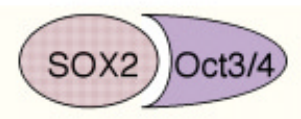

Target genes

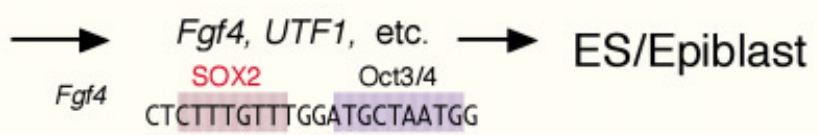

UTF1 SOX2 Oct3/4 CCCTCATTGTTATGCTAGTGAAG
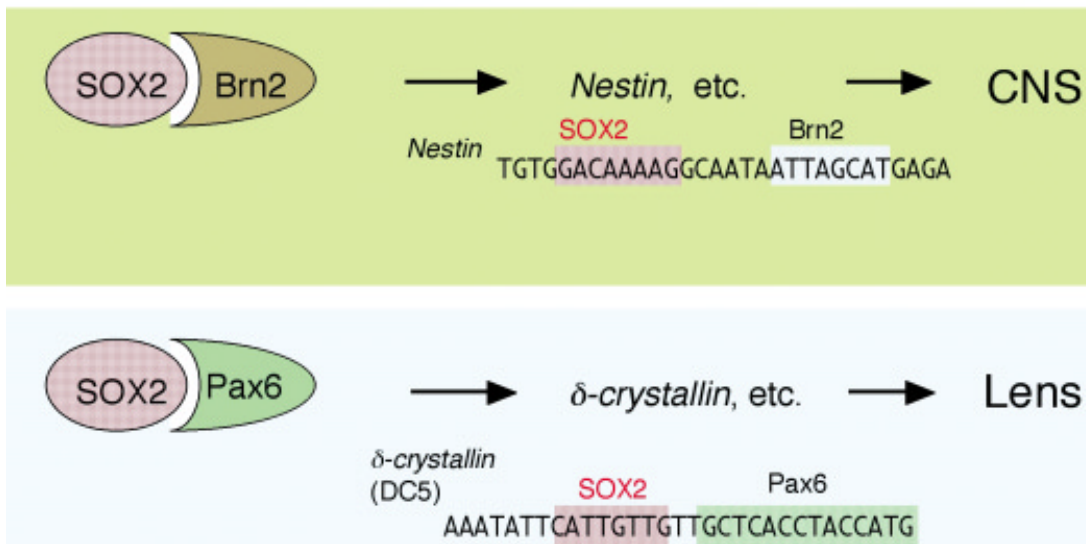

Fig. 8. (Above) SOX2 regulates distinct target genes in different cell types employing cell-specific partner factors (Kamachi, et al., 2000). In lens development, Pax6 is employed as the partner of SOX2 (bottom and Fig. 5), while Oct3/4 is the partner in the ES cells and epiblasts of the mouse (top), and Brn2 and other Class III POU factors are employed in the neuroectoderm and neural stem cells (middle). conserved sequences match perfectly with those functionally defined as enhancers. Therefore, these enhancers identified in the chicken genome based on functional criteria are generally conserved in mammalian genomes.

However, it is interesting to note that enhancer $L$ is not found in mammals. The lack of this lens fiberspecific regulatory element accounts for the absence of Sox2 expression in the lens fiber cells in the mouse (Kamachi et al., 1998).

\section{Partnership among transcription factors involving SOX proteins is a general mechanism of genetic switches for cell differentiation}

Through the series of investigations described above, we have shown that the encounter between two transcription factors, Pax6 and SOX2, initiates lens differentiation. In normal development, the encounter between these transcription factors is determined by temporal and spatial regulation of the individual transcription factor genes, and hence by the activities of enhancers associated with each of the genes. The Pax6 lens lineage enhancer initiates PaxG expression in a wide area of the head ectoderm starting before lens induction occurs (Williams, et al., 1998; Kammandel, et al., 1999; Xu, et al., 1999). On the other hand, Sox? enhancer N-4 activates low-level ectodermal expression of Sox2, which itself serves as the pilot light for the occurrence of the surge of Sox2 expression induced by contact of the optic vesicle. Once SOX2 and Pax6 protein meet in the same cells (Fig. 2), the cascades of transcriptional regulation for lens development are initiated. Thus, the combined action of SOX2 and Pax6 is essential for lens differentiation, and if this is effected in the early head ectoderm, it is sufficient for the initiation of lens development. SOX2 and Pax6 encounter each other in other tissues as well, e.g., in the neural retina and Rathke's pouch. In these tissues, lens-forming potential is generated, as manifested in cell 
culture or in yotzebrafish mutants, but the lens potency is suppressed by mechanisms that thereby direct differentiation into the respective tissues (shh signaling in the case of Rathke's pouch).

SOX, Pax and POU factors are often involved in the initiation of differentiation and/or defining a cell type. In the natural context, these transcription factors seldom function alone but use other transcription factors binding to an adjacent site as their functional partners.

When SOX2 cooperates with Pax6, it activates a set of genes for lens differentiation, whereas when it has Oct3/4 as its partner, it activates a battery of genes involved in establishing the epiblast/ ES cell state (Kamachi, et al., 2000). We have recently extended this scheme by showing that the combined action of SOX2 and Group III POU factors (e.g., Brn2) activates neural stem cellspecific genes, exemplified by Nestin (Tanaka et al., 2004).

These combinatorial codes of transcription factors, in particular factors of the SOX, Pax and POU family proteins, seem to be the major mechanism employed in genetic switches for cell differentiation (Kamachi, et al., 2000). The transcription factor combinatorial codes constitute a major mechanism by which transcription factors find the set of correct target genes among the vast amounts of nucleotide sequences contained in a genome. A transcription factor with a stringent six-base-pair recognition sequence recognizes 740,000 sites in a genome with a size of $3 \times 10^{9}$ base pairs, which is twenty times more than the number of genes contained in the whole genome, while the combinatorial of action of two such factors would select 180 sites. In reality, transcription factors bind to a number of sites showing considerable sequence variation, as we have seen in the case of Pax6 binding to the DC5 sequence. Therefore, transcription factors in the form of heterologous dimers will select the correct set of genomic sites for gene regulation. Moreover, alteration of only one component in the dimer will cause an overt change of the target sites and hence the genes under their regulation, and may be sufficient to elicit a different type of cell differentiation.

Thus, the interaction of Pax6 and SOX2 in the initiation of lens differentiation is not a mechanism pertinent only to lens tissue, but is a paradigm of genetic switching in global cell differentiation.

In this article, we did not try reviewing the lens development field, but focused on our research effort toward a goal, which has not changed throughout the period. This effort was not done in isolation, but was only possible in the wave of great advancement of the eye development field and by interaction with many leading groups partly represented in this special issue.

\section{Acknowledgements}

This study was initiated when one of the authors (HK) was in Professor T.S. Okada's laboratory. Most recent work was supported by a Human Frontier Science Program Grant (RGP0040/2001-M) and Grants-in-Aid for Scientific Research 12 CE2007 of Japan.

\section{References}

AOTA, S., NAKAJIMA, N., SAKAMOTO, R., WATANABE, S., IBARAKI, N. and OKAZAKI, K. (2003). Pax6 autoregulation mediated by direct interaction of pax6 protein with the head surface ectoderm-specific enhancer of the mouse pax6 gene. Dev Biol. 257:1-13.

BHAT, S. P., JONES, R. E., SULLIVAN, M. A. and PIATIGORSKY, J. (1980). Chicken lens crystallin DNA sequences show at least two delta-crystallin genes. Nature. 284:234-238.

CLAYTON, R. M. (1970). Problems of differentiation in the vertebrate lens. Curr Top Dev Biol. 5:115-180.
CLAYTON, R. M. and TRUMAN, D. E. (1967). Molecular structure and antigenicity of lens proteins. Nature. 214:1201-1204.

EDE, D. A. and KELLY, W. A. (1964). Developmental abnormalities in the head region of the talpid mutant of the fowl. J Embryol Exp Morphol. 12:161-182.

FEDTSOVA, N. G., MININA, T. A. and BARABANOV, V. M. (1981). [synthesis of a lens-specific antigen (delta-crystallin) in rudimentary chicken adenohypophysis]. Biull Eksp Biol Med. 92:314-316.

FUJIWARA, M., UCHIDA, T., OSUMI-YAMASHITA, N. and ETO, K. (1994). Uchida rat (rsey): A new mutant rat with craniofacial abnormalities resembling those of the mouse sey mutant. Differentiation. 57:31-38.

FUNAHASHI, J., KAMACHI, Y., GOTO, K. and KONDOH, H. (1991). Identification of nuclear factor delta ef1 and its binding site essential for lens-specific activity of the delta 1-crystallin enhancer. Nucleic Acids Res. 19:3543-3547.

FUNAHASHI, J., SEKIDO, R., MURAI, K., KAMACHI, Y. and KONDOH, H. (1993). Delta-crystallin enhancer binding protein delta ef1 is a zinc finger-homeodomain protein implicated in postgastrulation embryogenesis. Development. 119:433446.

FURUSAWA, T., MORIBE, H., KONDOH, H. and HIGASHI, Y. (1999). Identification of ctbp1 and ctbp2 as corepressors of zinc finger-homeodomain factor deltaef1. Mol Cell Biol. 19:8581-8590.

GENETTA, T., RUEZINSKY, D. and KADESCH, T. (1994). Displacement of an e-boxbinding repressor by basic helix-loop-helix proteins: Implications for b-cell specificity of the immunoglobulin heavy-chain enhancer. Mol Cell Biol. 14:6153-6163.

GOTO, K., OKADA, T. S. and KONDOH, H. (1990). Functional cooperation of lensspecific and nonspecific elements in the delta 1-crystallin enhancer. $\mathrm{Mo} / \mathrm{Ce} / \mathrm{Biol}$. 10:958-964

GRINDLEY, J. C., DAVIDSON, D. R. and HILL, R. E. (1995). The role of pax-6 in eye and nasal development. Development. 121:1433-1442.

HAYASHI, S., GOTO, K., OKADA, T. S. and KONDOH, H. (1987). Lens-specific enhancer in the third intron regulates expression of the chicken delta 1-crystallin gene. Genes Dev. 1:818-828.

HAYASHI, S., KONDOH, H., YASUDA, K., SOMA, G., IKAWA, Y. and OKADA, T. S. (1985). Tissue-specific regulation of a chicken delta-crystallin gene in mouse cells: Involvement of the 5' end region. EMBO J. 4:2201-2207.

HIGASHI, Y., MORIBE, H., TAKAGI, T., SEKIDO, R., KAWAKAMI, K., KIKUTANI, H. and $\mathrm{KONDOH}, \mathrm{H}$. (1997). Impairment of t cell development in deltaef1 mutant mice. J Exp Med. 185:1467-1479.

HILL, R. E., FAVOR, J., HOGAN, B. L., TON, C. C., SAUNDERS, G. F., HANSON, I. M., PROSSER, J., JORDAN, T., HASTIE, N. D. and VAN HEYNINGEN, V. (1991). Mouse small eye results from mutations in a paired-like homeoboxcontaining gene. Nature. 354:522-525.

HOGAN, B. L., HORSBURGH, G., COHEN, J., HETHERINGTON, C. M., FISHER, G. and LYON, M. F. (1986). Small eyes (sey): A homozygous lethal mutation on chromosome 2 which affects the differentiation of both lens and nasal placodes in the mouse. J Embryol Exp Morphol. 97:95-110.

JONES, R. E., BHAT, S. P., SULLIVAN, M. A. and PIATIGORSKY, J. (1980) Comparison of two delta-crystallin genes in the chicken. Proc Natl Acad Sci USA. 77:5879-5883.

JORDAN, T., HANSON, I., ZALETAYEV, D., HODGSON, S., PROSSER, J., SEAWRIGHT, A., HASTIE, N. and VAN HEYNINGEN, V. (1992). The human pax6 gene is mutated in two patients with aniridia. Nat Genet. 1:328-332.

KAMACHI, Y., CHEAH, K. S. and KONDOH, H. (1999). Mechanism of regulatory target selection by the sox high-mobility-group domain proteins as revealed by comparison of sox1/2/3 and sox9. Mol Cell Biol. 19:107-120.

$\mathrm{KAMACHI}, \mathrm{Y}$. and $\mathrm{KONDOH}, \mathrm{H}$. (1993). Overlapping positive and negative regulatory elements determine lens-specific activity of the delta 1-crystallin enhancer. Mol Cell Biol. 13:5206-5215.

KAMACHI, Y., SOCKANATHAN, S., LIU, Q., BREITMAN, M., LOVELL-BADGE, R and $\mathrm{KONDOH}, \mathrm{H}$. (1995). Involvement of sox proteins in lens-specific activation of crystallin genes. EMBO J. 14:3510-3519.

KAMACHI, Y., UCHIKAWA, M., COLLIGNON, J., LOVELL-BADGE, R. and $\mathrm{KONDOH}, \mathrm{H}$. (1998). Involvement of sox 1,2 and 3 in the early and subsequent molecular events of lens induction. Development. 125:2521-2532.

KAMACHI, Y., UCHIKAWA, M. and KONDOH, H. (2000). Pairing sox off: With partners in the regulation of embryonic development. Trends Genet. 16:182187. 
KAMACHI, Y., UCHIKAWA, M., TANOUCHI, A., SEKIDO, R. and KONDOH, H. (2001). Pax6 and sox2 form a co-DNA-binding partner complex that regulates initiation of lens development. Genes Dev. 15:1272-1286.

KAMMANDEL, B., CHOWDHURY, K., STOYKOVA, A., APARICIO, S., BRENNER, S. and GRUSS, P. (1999). Distinct cis-essential modules direct the time-space pattern of the pax6 gene activity. Dev Biol. 205:79-97.

KARLSTROM, R. O., TALBOT, W. S. and SCHIER, A. F. (1999). Comparative synteny cloning of zebrafish you-too: Mutations in the hedgehog target gli2 affect ventral forebrain patterning. Genes Dev. 13:388-393.

KAWAUCHI, S., TAKAHASHI, S., NAKAJIMA, O., OGINO, H., MORITA, M., NISHIZAWA, M., YASUDA, K. and YAMAMOTO, M. (1999). Regulation of lens fiber cell differentiation by transcription factor c-maf. J Biol Chem. 274:1925419260.

KIM, J. I., LI, T., HO, I. C., GRUSBY, M. J. and GLIMCHER, L. H. (1999). Requirement for the c-maf transcription factor in crystallin gene regulation and lens development. Proc Nat/ Acad Sci USA. 96:3781-3785.

$\mathrm{KONDOH}, \mathrm{H}$. (1999). Transcription factors for lens development assessed in vivo. Curr Opin Genet Dev. 9:301-308.

KONDOH, H., KATOH, K., TAKAHASHI, Y., FUJISAWA, H., YOKOYAMA, M., KIMURA, S., KATSUKI, M., SAITO, M., NOMURA, T., HIRAMOTO, Y. et al. (1987). Specific expression of the chicken delta-crystallin gene in the lens and the pyramidal neurons of the piriform cortex in transgenic mice. Dev Biol. 120:177-185

KONDOH, H., TAKAHASHI, Y. and OKADA, T. S. (1984). Differentiation-dependent expression of the chicken delta-crystallin gene introduced into mouse teratocarcinoma stem cells. EMBO J. 3:2009-2014.

KONDOH, H., UCHIKAWA, M., YODA, H., TAKEDA, H., FURUTANI-SEIKI, M. and KARLSTROM, R. O. (2000). Zebrafish mutations in gli-mediated hedgehog signaling lead to lens transdifferentiation from the adenohypophysis anlage. Mech Dev. 96:165-174.

KONDOH, H., UEDA, Y., HAYASHI, S., OKAZAKI, K., YASUDA, K. and OKADA, T.S. (1987). An attempt to assay the state of determination by using transfected genes as probes in transdifferentiation of neural retina into lens. Cell Differ. 20:203-207.

KONDOH, H., YASUDA, K. and OKADA, T. S. (1983). Tissue-specific expression of a cloned chick delta-crystallin gene in mouse cells. Nature. 301:440-442.

LEWIS, K. E., DROSSOPOULOU, G., PATON, I. R., MORRICE, D. R., ROBERTSON, K. E., BURT, D. W., INGHAM, P. W. and TICKLE, C. (1999). Expression of ptc and gli genes in talpid3 suggests bifurcation in shh pathway. Development. 126:2397-2407.

LI, H. S., YANG, J. M., JACOBSON, R. D., PASKO, D. and SUNDIN, O. (1994). Pax6 is first expressed in a region of ectoderm anterior to the early neural plate: Implications for stepwise determination of the lens. Dev Biol. 162:181-194.

LIU, Q. R., TINI, M., TSUI, L. C. and BREITMAN, M. L. (1991). Interaction of a lens cell transcription factor with the proximal domain of the mouse gamma $f$ crystallin promoter. Mol Cell Biol. 11:1531-1537.

LOK, S., STEVENS, W., BREITMAN, M. L. and TSUI, L. C. (1989). Multiple regulatory elements of the murine gamma 2-crystallin promoter. Nucleic Acids Res. 17:3563-3582.

MUTA, M., KAMACHI, Y., YOSHIMOTO, A., HIGASHI, Y. and KONDOH, H. (2002). Distinct roles of sox2, pax 6 and maf transcription factors in the regulation of lens-specific delta1-crystallin enhancer. Genes Cells. 7:791-805.

NISHIGUCHI, S., WOOD, H., KONDOH, H., LOVELL-BADGE, R. and EPISKOPOU, V. (1998). Sox1 directly regulates the gamma-crystallin genes and is essential for lens development in mice. Genes Dev. 12:776-781.

OGINO, H. and YASUDA, K. (1998). Induction of lens differentiation by activation of a bzip transcription factor, I-maf. Science. 280:115-118.

OKADA, T. S. (1980). Cellular metaplasia or transdifferentiation as a model for retinal cell differentiation. Curr Top Dev Biol. 16:349-380.
OKADA, T.S., YASUDA, K., ARAKI, M. and EGUCHI, G. (1979). Possible demonstration of multipotential nature of embryonic neural retina by clonal cell culture. Dev Biol. 68:600-617.

REZA, H. M., OGINO, H. and YASUDA, K. (2002). L-maf, a downstream target of pax6, is essential for chick lens development. Mech Dev. 116:61-73.

RING, B. Z., CORDES, S. P., OVERBEEK, P. A. and BARSH, G. S. (2000). Regulation of mouse lens fiber cell development and differentiation by the maf gene. Development. 127:307-317.

SEKIDO, R., MURAI, K., FUNAHASHI, J., KAMACHI, Y., FUJISAWA-SEHARA, A., NABESHIMA, Y. and KONDOH, H. (1994). The delta-crystallin enhancer-binding protein delta ef1 is a repressor of e2-box-mediated gene activation. Mol Cell Biol. 14:5692-5700.

SEKIDO, R., MURAI, K., KAMACHI, Y. and KONDOH, H. (1997). Two mechanisms in the action of repressor deltaef1: Binding site competition with an activator and active repression. Genes Cells. 2:771-783.

SHIMADA, N., AYA-MURATA, T., REZA, H. M. and YASUDA, K. (2003). Cooperative action between I-maf and sox2 on delta-crystallin gene expression during chick lens development. Mech Dev. 120:455-465.

SHINOHARA, T. and PIATIGORSKY, J. (1976). Quantitation of delta-crystallin messenger rna during lens induction in chick embryos. Proc Natl Acad Sci USA. 73:2808-2812.

TAKAGI, T., MORIBE, H., KONDOH, H. and HIGASHI, Y. (1998). Deltaef1, a zinc finger and homeodomain transcription factor, is required for skeleton patterning in multiple lineages. Development. 125:21-31.

TAKAHASHI, Y., HANAOKA, K., HAYASAKA, M., KATOH, K., KATO, Y., OKADA, T. $\mathrm{S}$. and $\mathrm{KONDOH}, \mathrm{H}$. (1988). Embryonic stem cell-mediated transfer and correct regulation of the chicken delta-crystallin gene in developing mouse embryos. Development. 102:259-269.

TANAKA, S., KAMACHI, Y., TANAUCHI, A., HAMADA, H., JING, N. and KONDOH, $H$. (2004). Interplay of SOX and POU factors in regulation of the Nestin gene in neural primordial cells. Mol. Cell. Biol. 24: 8834-8846.

UCHIKAWA, M., ISHIDA, Y., TAKEMOTO, T., KAMACHI, Y. and KONDOH, H. (2003). Functional analysis of chicken sox2 enhancers highlights an array of diverse regulatory elements that are conserved in mammals. Dev Cell. 4:509-519.

UCHIKAWA, M., KAMACHI, Y. and KONDOH, H. (1999). Two distinct subgroups of group b sox genes for transcriptional activators and repressors: Their expression during embryonic organogenesis of the chicken. Mech Dev. 84:103-120.

UEDA, Y. and OKADA, T. S. (1986). Transient expression of a 'lens-specific' gene, delta-crystallin, in the embryonic chicken adenohypophysis. Cell Differ. 19:179185.

VAN DE PUTTE, T., MARUHASHI, M., FRANCIS, A., NELLES, L., KONDOH, H., HUYLEBROECK, D. and HIGASHI, Y. (2003). Mice lacking $z f h \times 1 b$, the gene that codes for smad-interacting protein-1, reveal a role for multiple neural crest cell defects in the etiology of hirschsprung disease-mental retardation syndrome. $A m J$ Hum Genet. 72:465-470.

VARGA, Z. M., AMORES, A., LEWIS, K. E., YAN, Y. L., POSTLETHWAIT, J. H., EISEN, J. S. and WESTERFIELD, M. (2001). Zebrafish smoothened functions in ventral neural tube specification and axon tract formation. Development. 128:3497-3509.

WILLIAMS, S. C., ALTMANN, C. R., CHOW, R. L., HEMMATI-BRIVANLOU, A. and LANG, R. A. (1998). A highly conserved lens transcriptional control element from the pax-6 gene. Mech Dev. 73:225-229.

XU, P. X., ZHANG, X., HEANEY, S., YOON, A., MICHELSON, A. M. and MAAS, R. L. (1999). Regulation of pax6 expression is conserved between mice and flies. Development. 126:383-395.

YASUDA, K., KONDOH, H., OKADA, T. S., NAKAJIMA, N. and SHIMURA, Y. (1982). Organization of delta-crystallin genes in the chicken. Nucleic Acids Res. 10:28792891.

YASUDA, K., NAKAJIMA, N., ISOBE, T., OKADA, T. S. and SHIMURA, Y. (1984). The nucleotide sequence of a complete chicken delta-crystallin cdna. EMBO J. 3:1397-1402. 